\title{
miR-217 and miR-543 downregulation mitigates inflammatory response and myocardial injury in children with viral myocarditis by regulating the SIRT1/AMPK/NF-кB signaling pathway
}

\author{
KUN XIA, YONG ZHANG and DONGMING SUN \\ Department of Cardiovascular Medicine, Wuhan Children's Hospital, Tongji Medical College, \\ Huazhong University of Science and Technology, Wuhan, Hubei 430019, P.R China
}

Received April 17, 2019; Accepted September 5, 2019

DOI: $10.3892 / \mathrm{ijmm} .2019 .4442$

\begin{abstract}
The aim of the present study was to investigate the expression levels and roles of microRNA (miR)-217 and miR-543 in viral myocarditis, and to examine their underlying mechanisms. Coxsackievirus B3 (CVB3) was used to establish in vivo and in vitro models of viral myocarditis. The levels of miR-217 and miR-543 were detected using reverse transcription-quantitative PCR. The association between miR-217 and miR-543 and sirtuin-1 (SIRT1) was predicted and confirmed by TargetScan and dual-luciferase reporter assay. Cell viability was detected using Cell Counting Kit-8 assay, and cell apoptosis was measured by analyzing the expression levels of Bcl-2 and Bax, and by flow cytometry. In addition, the synthesis of various pro-inflammatory factors was determined by ELISA. In addition, superoxide dismutase (SOD) activity and malondialdehyde (MDA) levels were measured in cardiomyocytes following transfection and CVB infection. miR-217 and miR-543 were found to be highly expressed in the peripheral blood of pediatric patients with viral myocarditis, in the peripheral blood and myocardial tissues of viral myocarditis mice and in CVB3-infected cardiomyocytes. SIRT1 was found to be a target of both miR-217 and miR-543, and SIRT1 expression level was downregulated in viral myocarditis. Further analysis indicated that the reduced cell viability, increased cell apoptosis, enhanced synthesis of inflammatory factors, increased MDA content and decreased SOD activity associated with myocarditis were significantly reversed after inhibition of miR-217 or miR-543. Importantly, the present results showed that all the effects of miR-217 and miR-543 inhibition on cardiomyocytes were significantly
\end{abstract}

Correspondence to: Dr Yong Zhang, Department of Cardiovascular Medicine, Wuhan Children's Hospital, Tongji Medical College, Huazhong University of Science and Technology, 100 Hong Kong Road, Wuhan, Hubei 430019, P.R. China

E-mail: zhangyong190130@163.com

Key words: viral myocarditis, cardiomyocytes, microRNA-217, microRNA-543, sirtuin-1 suppressed following SIRT1 knockdown. Collectively, the present data indicated that miR-217 and miR-543 were significantly upregulated in viral myocarditis, and downregulation of miR-217 and miR-543 attenuated CVB3 infection-induced cardiomyocyte injury by targeting SIRT1. miR-217 and miR-543 may be potential therapeutic targets for developing novel viral myocarditis treatments in the future.

\section{Introduction}

Viral myocarditis (VMC) is the most common type of myocarditis, and it is mainly caused by Coxsackievirus B (CVB) infection (1-3). In total, $\sim 20 \%$ of sudden mortalities in infants are due to viral myocarditis or fatal ventricular arrhythmias caused by viral myocarditis $(4,5)$. The prognosis of patients with persistent viral myocarditis is poor, and the incidence of viral myocarditis has increased in the past years (6). Viral myocarditis is a serious threat to pediatric health (7). Chronic inflammation of myocardial cells can cause myocardial cell growth inhibition, hypertrophy, apoptosis and myocardial fibrosis, thus causing dilated cardiomyopathy and heart failure $(8,9)$. The currently available treatments for viral myocarditis remain unsatisfactory. Therefore, it is important to study the molecular mechanism of the pathogenesis of viral myocarditis and to identify new effective diagnostic and therapeutic targets.

MicroRNAs (miRNAs) are a class of small endogenous non-coding RNAs that can post-transcriptionally regulate gene expression by binding to the 3 '-untranslated region (UTR) of target mRNAs (10-12). miRNAs have been identified to play important roles in the regulation of various biological processes, including cell proliferation, differentiation and apoptosis (13-15). In addition, miRNAs are considered to be involved in the regulation of vascular proliferation, cardiac development, heart failure and cardiac hypertrophy (16-18). Several miRNAs, including miR-155, miR-21, miR-146a, miR-208b, miR-499-5p and miR-148a, have been reported to play important roles in the pathogenesis of viral myocarditis (19-21).

Sirtuin 1 (SIRT1) is a NAD ${ }^{+}$-dependent deacetylase and it is important for cell apoptosis (22). Previous studies have indicated that SIRT1 plays an important role in the regulation 
of oxidative stress and inflammatory response (23-26). SIRT1 overexpression and SIRT1 activator SRT1720 treatment could attenuate renal lipid content and expression of lipogenesis, oxidative stress and inflammatory markers in mice (27). SIRT1 controls acetaminophen hepatotoxicity by regulating inflammation and oxidative stress (24). SIRT1 activation could attenuate inflammation and premature senescence involved in chronic lung diseases (28). In addition, a previous study indicated that SIRT1 attenuates endoplasmic reticulum stress-induced cardiomyocyte apoptosis by regulating PERK/eIF2 $\alpha$, ATF6/CHOP, and IRE1 $\alpha /$ JNK pathways (29). A number of other studies have also demonstrated the important regulatory role of SIRT1 in cardiomyocyte apoptosis (30-32). In addition, SIRT1 has been found to be a target of miR-543 $(33,34)$ and miR-217 $(35)$. Collectively, the present results suggested that miR-543 and miR-217 may have a role in viral myocarditis development by regulating the inflammatory response and cardiomyocyte apoptosis via SIRT1. To the best of our knowledge, the expression levels and roles of miR-543 and miR-217 in viral myocarditis, and the relationship between miR-543, miR-217 and SIRT1 in cardiomyocytes remain unclear.

Therefore, the aim of the present study was to investigate the expression levels and role of miR-217 and miR-543 in viral myocarditis, and to explore their underlying mechanism.

\section{Materials and methods}

Clinical samples. In total, 30 children (female to male ratio, 13:17; age range, between 9 months and 12 years) with viral myocarditis and healthy volunteers were enrolled at Wuhan Children's Hospital between May 2015 and May 2017. Blood samples $(500 \mu \mathrm{l})$ were collected from each participant. Informed consent was obtained from each patient and the parents or the legal guardians of the patients. The present study was approved by The Ethics Committee of Wuhan Children's Hospital.

Animal experiments. In total, 40 male BALB/C mice (weight, 18-22 g; age, 4 weeks) were obtained from Vital River Laboratories Co., Ltd. Mice were housed at $25 \pm 5^{\circ} \mathrm{C}$, with $50-70 \%$ humidity, with a 12-h dark/light cycle and free access to food and water. The in vivo animal experiments were carried out according to the to the National Institutes of Health Guide for the Care and Use of Laboratory Animals (36). This study was approved by The Animal Ethics Committee of Tongji Medical College, Huazhong University of Science and Technology.

The mice were divided into two groups: i) Control group (mice were not infected and were intraperitoneally injected with $0.2 \mathrm{ml} \mathrm{PBS}$ ); and ii) CVB3 infection group (1 h after intraperitoneal injection with $10^{3}$ TCID50 of CVB3 virus, the mice were injected with $0.2 \mathrm{ml}$ PBS). The CVB3 strain used in the present study was obtained from The Center for Endemic Disease Control of China. The CVB3 was amplified in HeLa cells (American Type Culture Collection) according to a previous study (37). Mice in the CVB3 infection group were injected with CVB3 for three days, and sacrificed on day 21. At day 21, the peripheral blood was collected and stored at $-20^{\circ} \mathrm{C}$. After the mice were sacrificed by decapita- tion, myocardial tissues were harvested and stored in liquid nitrogen until use.

Cell culture and infection. Embryonic rat heart-derived H9C2 cells and HeLa cells were obtained from The American Type Culture Collection. All cells were grown in DMEM (Gibco; Thermo Fisher Scientific, Inc.) containing 10\% FBS (Gibco; Thermo Fisher Scientific, Inc.), $1 \%$ streptomycin-penicillin solution and maintained at $37^{\circ} \mathrm{C}$ with $5 \% \mathrm{CO}_{2}$.

CVB3 infection in $\mathrm{H} 9 \mathrm{C} 2$ cells was performed by treating $\mathrm{H} 9 \mathrm{C} 2$ cells with $10^{4} \mathrm{PFU} / \mathrm{ml} \mathrm{CVB} 3$ virus. H9C2 cells were randomly divided into the following groups: i) Control group, normal H9c2 cells without any treatment; ii) CVB3 group, $\mathrm{H} 9 \mathrm{C} 2$ cells treated with $10^{4} \mathrm{PFU} / \mathrm{ml} \mathrm{CVB3}$ virus, as previously described (38); iii) CVB3 + inhibitor control-1 group, H9C2 cells were transfected with the inhibitor control of miR-217 for $48 \mathrm{~h}$ and then treated with $10^{4} \mathrm{PFU} / \mathrm{ml}$ CVB3 virus; iv) CVB3+ miR-217 inhibitor group (CVB3 + miR-217 inhibitor), H9C2 cells were transfected with miR-217 inhibitor for $48 \mathrm{~h}$ and then treated with $10^{4} \mathrm{PFU} / \mathrm{ml} \mathrm{CVB} 3$ virus; v) CVB3 + miR-217 inhibitor + SIRT1-small interfering (si) RNA group (CVB3 + miR-217 inhibitor + SIRT1-siRNA), H9C2 cells were co-transfected with miR-217 inhibitor and SIRT1-siRNA for $48 \mathrm{~h}$ and then treated with $10^{4} \mathrm{PFU} / \mathrm{ml} \mathrm{CVB} 3$ virus; vi) $\mathrm{CVB} 3+$ inhibitor control-2 group, H9C2 cells were transfected with the inhibitor control of miR-543 for $48 \mathrm{~h}$ and then treated with $10^{4} \mathrm{PFU} / \mathrm{ml} \mathrm{CVB3}$ virus; vii) CVB3+ miR-543 inhibitor group (CVB3 + miR-543 inhibitor), H9C2 cells were transfected with the miR-543 inhibitor for $48 \mathrm{~h}$ and then treated with $10^{4} \mathrm{PFU} / \mathrm{ml}$ CVB3 virus; viii) $\mathrm{CVB} 3+$ miR-543 inhibitor + SIRT1-siRNA group (CVB3 + miR-543 inhibitor + SIRT1-siRNA), H9C2 cells were co-transfected with miR-543 inhibitor and SIRT1-siRNA for $48 \mathrm{~h}$ and then treated with $10^{4} \mathrm{PFU} / \mathrm{ml} \mathrm{CVB3}$ virus for $48 \mathrm{~h}$.

Cell transfection. H9C2 cells were seeded into six-well plates $\left(1 \times 10^{6}\right.$ cells/well) and cultured at $37^{\circ} \mathrm{C}$ for $24 \mathrm{~h}$. Then, H9C2 cells were transfected with the $100 \mathrm{nM}$ inhibitor control of miR-217 inhibitor (inhibitor control-1: 5'-GCCUCCGGCUUC GCACCUCU-3'), $100 \mathrm{nM}$ inhibitor control of miR-543 inhibitor (inhibitor control-2: 5'-CAGUACUUUUGUGUAGUA CAA-3'), $100 \mathrm{nM}$ miR-217 inhibitor (5'-UACUGCAUCAGG AACUGAUUGGA-3'), $100 \mathrm{nM}$ miR-543 inhibitor (5'-AAG AAGUGCACCGCGAAUGUUU-3'), $1 \mu \mathrm{M}$ control-siRNA (cat. no. sc-36869; Santa Cruz Biotechnology, Inc.), $1 \mu \mathrm{M}$ SIRT1-siRNA (cat. no. sc-40986; Santa Cruz Biotechnology, Inc.), $100 \mathrm{nM}$ miR-217 inhibitor $+1 \mu \mathrm{M}$ SIRT1-siRNA or $100 \mathrm{nM}$ miR-543 inhibitor $+1 \mu \mathrm{M}$ SIRT1-siRNA by using Lipofectamine ${ }^{\circledR} 2000$ (Invitrogen; Thermo Fisher Scientific, Inc.) according to the manufacturer's protocol. After $48 \mathrm{~h}$ of cell transfection, transfection efficiency was detected using reverse transcription-quantitative (RT-q)PCR.

$R T-q P C R$. Total RNA from blood samples and cells was collected using TRIzol ${ }^{\circledR}$ reagent (Invitrogen; Thermo Fisher Scientific, Inc.) according to the manufacturer's protocol. Total RNA was reverse transcribed into cDNA using the PrimeScript RT Reagent Kit (Takara Bio, Inc.) according to the manufacturer's protocol. The temperature protocol for the 

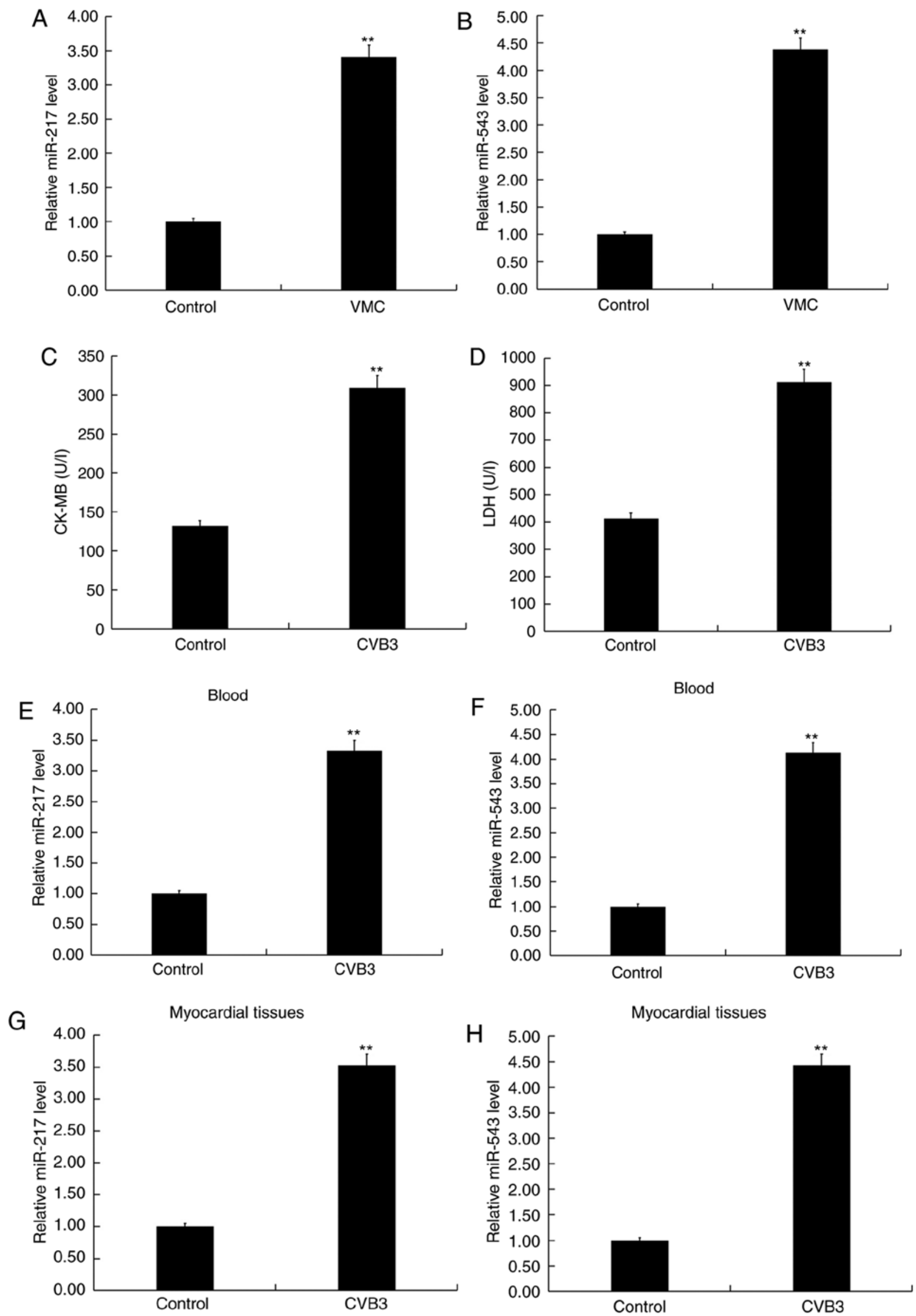

Figure 1. Expression of miR-217 and miR-543 in viral myocarditis. Expression levels of (A) miR-217 and (B) miR-543 in the blood samples from healthy volunteers and in the blood from pediatric patients with viral myocarditis were detected using reverse transcription-quantitative PCR. The levels of (C) CK-MB and (D) LDH in the blood of healthy control mice and CVB3-infected mice. Expression levels of (E) miR-217 and (F) miR-543 in the blood samples of healthy control mice and CVB3-infected mice. Expression levels of $(\mathrm{G}) \mathrm{miR}-217$ and $(\mathrm{H})$ miR-543 in the myocardial tissues of healthy control mice and CVB3-infected mice. Data are presented as the mean $\pm \mathrm{SD}$. ${ }^{* *} \mathrm{P}<0.01$ vs. corresponding control. 

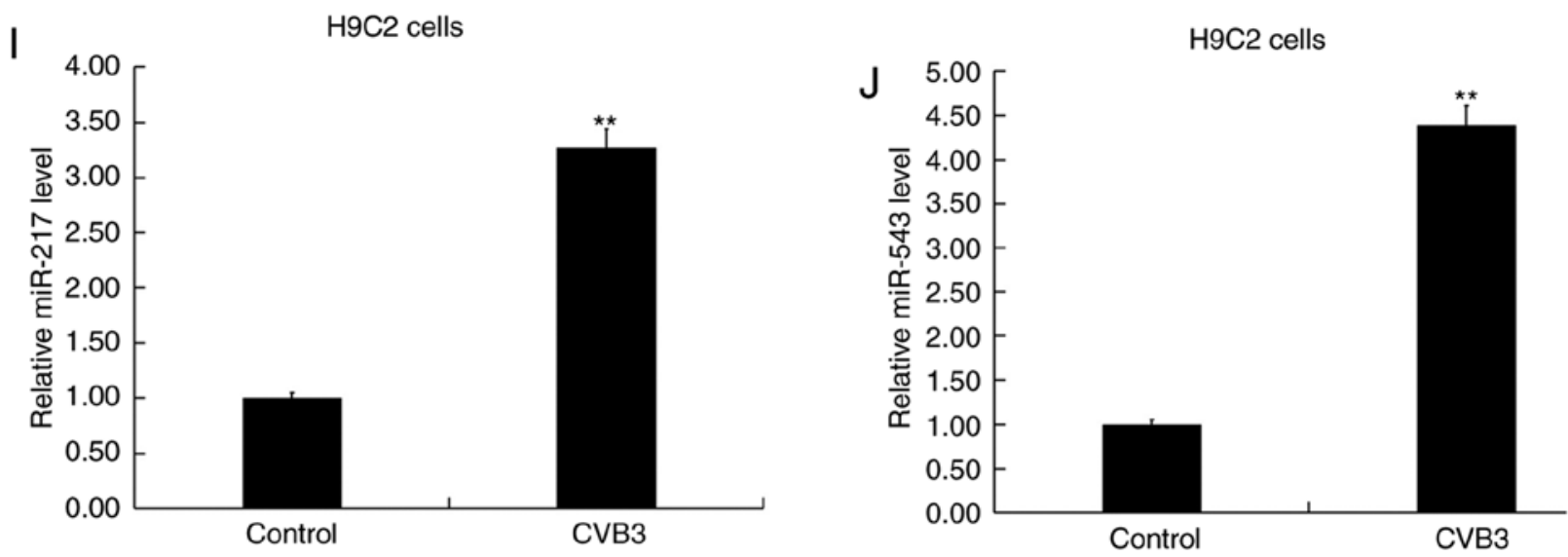

Figure 1. Contiued. Expression of miR-217 and miR-543 in viral myocarditis. Expression levels of (I) miR-217 and (J) miR-543 in H9C2 cells infected with CVB3. Data are presented as the mean $\pm \mathrm{SD}$. ${ }^{* *} \mathrm{P}<0.01$ vs. corresponding control. VMC, viral myocarditis; miR, microRNA; CVB3, Coxsackievirus B3; CK-MB, creatine kinase; $\mathrm{LDH}$, lactate dehydrogenase.

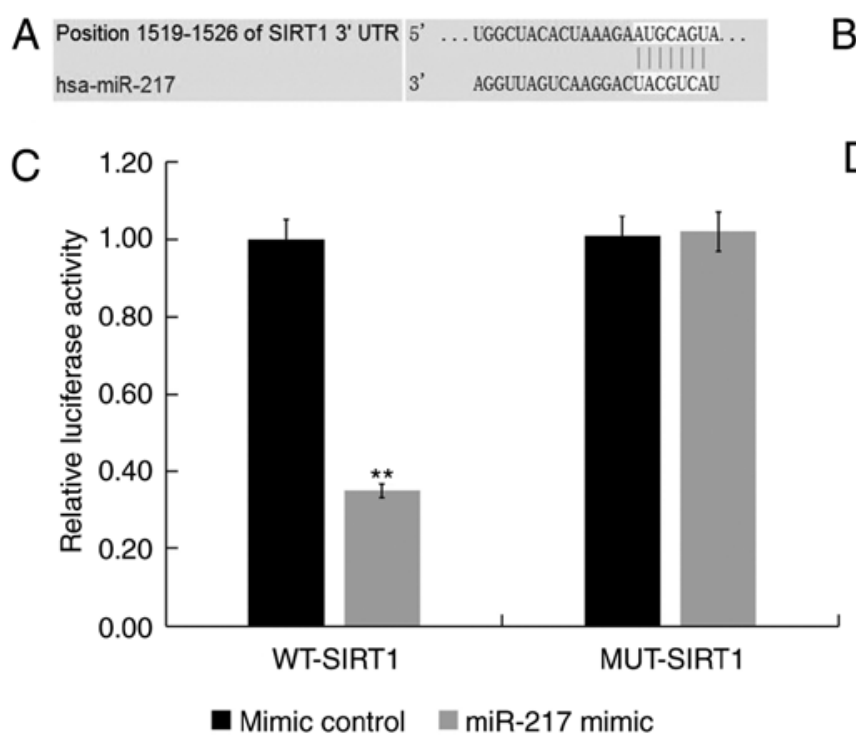
B Position 64-70 of SIRT1 3' UTR hsa-miR-543
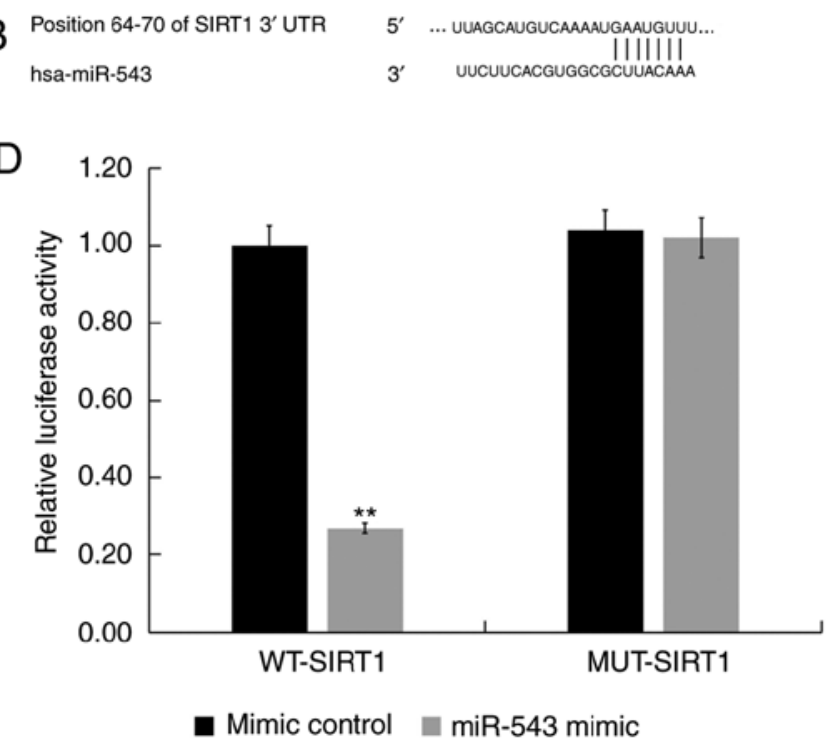

Figure 2. SIRT1 is a target of miR-217 and miR-543. TargetScan predicted the binding sites of (A) miR-217 and (B) miR-543 in the 3 'UTR of SIRT1. Luciferase activity following (C) miR-217 and (D) miR-543 overexpression was determined using a dual-luciferase reporter assay. ${ }^{* *} \mathrm{P}<0.01 \mathrm{vs}$. mimic control. UTR, untranslated region; WT, wild-type; MUT, mutant; SIRT1, sirtuin 1; miR, microRNA.

reverse transcription reaction was as follows: $25^{\circ} \mathrm{C}$ for $5 \mathrm{~min}$, $42^{\circ} \mathrm{C}$ for $60 \mathrm{~min}$ and $80^{\circ} \mathrm{C}$ for $2 \mathrm{~min}$. cDNAs were analyzed by RT-qPCR using SYBR Premix Ex Taq (Takara Bio, Inc.) according to the manufacturer's instructions. The amplification conditions were as following: Initial denaturation at $95^{\circ} \mathrm{C}$ for $5 \mathrm{~min}$, followed by 40 cycles of $95^{\circ} \mathrm{C}$ for $15 \mathrm{sec}$ and $60^{\circ} \mathrm{C}$ for $30 \mathrm{sec}$. The primer sequences used for the RT-qPCR were as follows: miR-543 forward 5'-CAGTGCTAAAAC ATTCGCGG-3' and reverse 5'-TATGGTTGTTCACGA CTCCTTCAC-3'; miR-217 forward 5'-TACTGCATCAGG AACTGACTGGA-3'; and reverse 5'-GTGCAGGGTCCGA GGT-3'; U6 forward 5'-GCTTCGGCAGCACATATACTA AAAT-3' and reverse 5'-CGCTTCACGAATTTGCGTGT CAT-3'; SIRT1 forward 5'-AATCCAGTCATTAAAGGTCTA CAA-3' and reverse 5'-TAGGACCATTACTGCCAGAGG-3'; GAPDH forward 5'-CTTTGGTATCGTGGAAGGACTC-3' and reverse 5'-GTAGAGGCAGGGATGATGTTCT-3'. U6 and GAPDH were used as the internal controls to normalize the expression level of miRNA and mRNA, respectively. The relative gene expression was calculated using the $2^{-\Delta \Delta \mathrm{Cq}}$ method (39).

Western blotting. Total protein from cells was harvested using a RIPA tissue/cell lysis buffer (cat. no. R0010; Beijing Solarbio Science \& Technology Co., Ltd.). Bicinchoninic acid assay (Thermo Fisher Scientific, Inc.) was performed to determine the protein concentrations. Equal amount of protein $(25 \mu \mathrm{g} / \mathrm{lane})$ was separated by $12 \%$ SDS-PAGE and transferred to PVDF (Roche). Then, after blocking with 5\% non-fat milk for $1 \mathrm{~h}$ at room temperature, the membranes were incubated with the following primary antibodies: SIRT1 (1:1,000; cat. no. 9475; Cell Signaling Technology, Inc.), phosphorylated (p)-AMP-activated protein kinase- $\alpha$ (p-AMPK- $\alpha$; 1: 1,000; cat. no. 50081; Cell Signaling Technology, Inc.), AMPK- $\alpha$ (1:1,000; cat. no. 5831; Cell Signaling Technology, Inc.), p65 (1:1,000; cat. no. 8242; Cell Signaling Technology, Inc.), p-NF-кB p65 (p-p65; 1:1,000; 

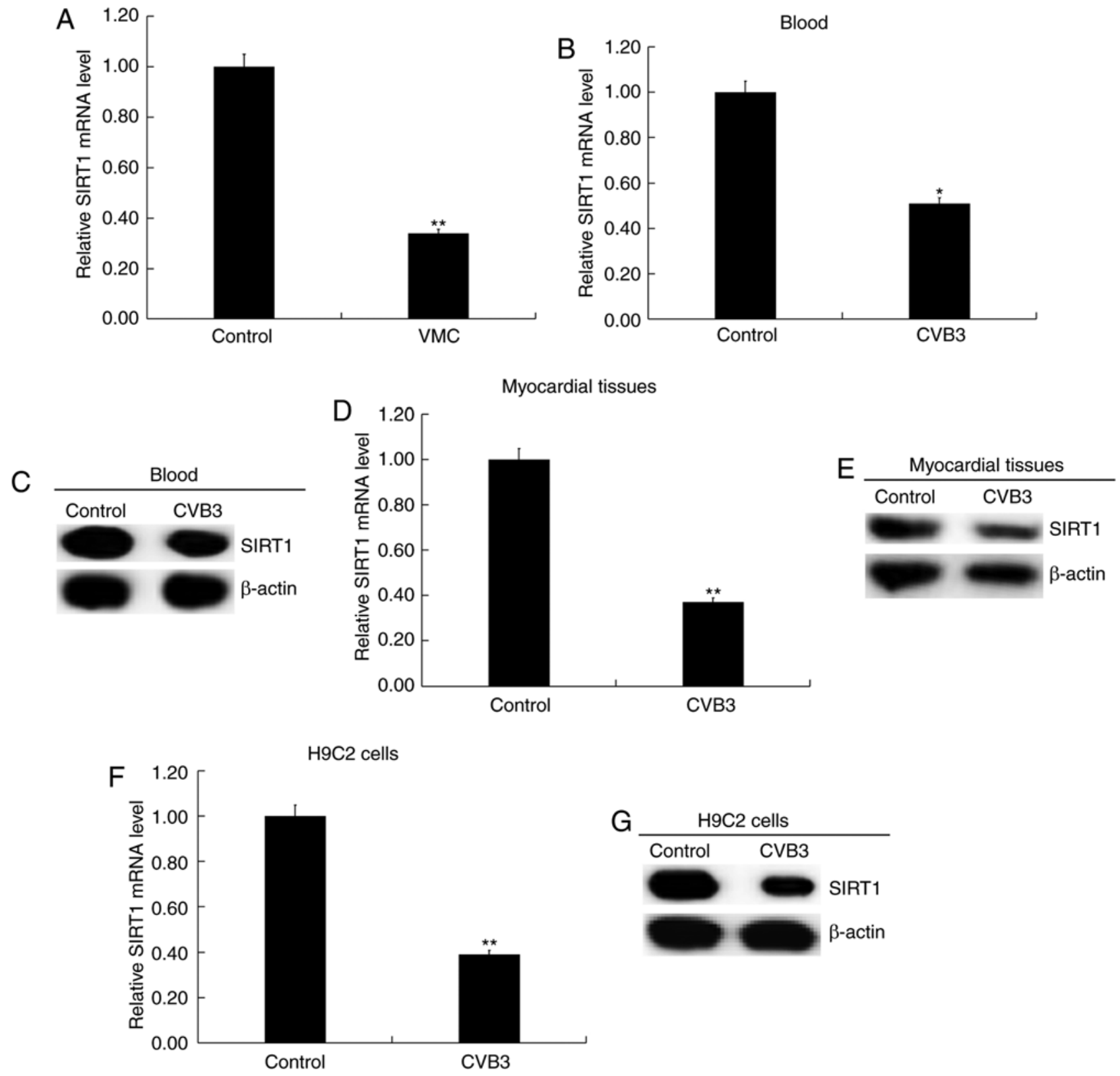

Figure 3. Expression of SIRT1 in viral myocarditis. (A) Expression levels of SIRT1 in blood samples from healthy volunteers and from pediatric patients with viral myocarditis were detected using reverse transcription-quantitative PCR. SIRT1 (B) mRNA and (C) protein levels were detected in the blood of healthy control mice and CVB3-infected mice. SIRT1 (D) mRNA and (E) protein levels were detected in the myocardial tissue of healthy control and CVB3-infected mice. (F) mRNA and (G) protein levels of SIRT1 in H9C2 cells infected with CVB3. Data are presented as the mean \pm SD. ${ }^{* *} \mathrm{P}<0.01$ vs. corresponding control. VMC, viral myocarditis; miR, microRNA; CVB3, Coxsackievirus B3; SIRT1, sirtuin 1.

cat. no. 3033; Cell Signaling Technology, Inc.), Bax (1:1,000; cat. no. 14796; Cell Signaling Technology, Inc.), Bcl-2 (1:1,000; cat. no. ab196495; Abcam), and $\beta$-actin (1:1,000; cat. no. 4970; Cell Signaling Technology, Inc.), overnight at $4^{\circ} \mathrm{C}$, followed by incubation with horseradish peroxidase-conjugated goat anti-rabbit immunoglobulin G secondary antibody $(1: 2,000$; cat. no. 7074; Cell Signaling Technology, Inc.) at room temperature for $1 \mathrm{~h}$. An ECL system (Pierce; Thermo Fisher Scientific, Inc.) was used to visualize protein bands according to the manufacturer's instructions and proteins were quantified using Quantity One Image software (version 4.6; Bio-Rad Laboratories, Inc.).

CCK- 8 assay. After treatment, CCK- 8 assay was used to analyze cell viability. Sells were seeded in 96 -well plates
(Corning Inc.) and incubated for $48 \mathrm{~h}$ at $37^{\circ}$. Subsequently, $10 \mu \mathrm{g} / \mathrm{ml} \mathrm{CCK}-8$ solution was added to each well, and the cells were then incubated at $37^{\circ}$ for $4 \mathrm{~h}$. The optical density was detected at a wavelength of $450 \mathrm{~nm}$ using a micro-plate reader (Thermo Fisher Scientific, Inc.).

Cell apoptosis assay. The Annexin V-FITC/propidium iodide (PI) apoptosis detection kit (cat. no. 70-AP101-100; MultiSciences) was used to analyze cell apoptosis. Following indicated treatments, cells were collected with $0.25 \%$ trypsin, washed with PBS, and then stained with $5 \mu$ l Annexin V-FITC and $5 \mu \mathrm{l} \mathrm{PI}$ for $30 \mathrm{~min}$ at room temperature in the dark. Finally, flow cytometry (BD Biosciences) was performed to analyze cell apoptosis, and data were analyzed using WinMDI software 

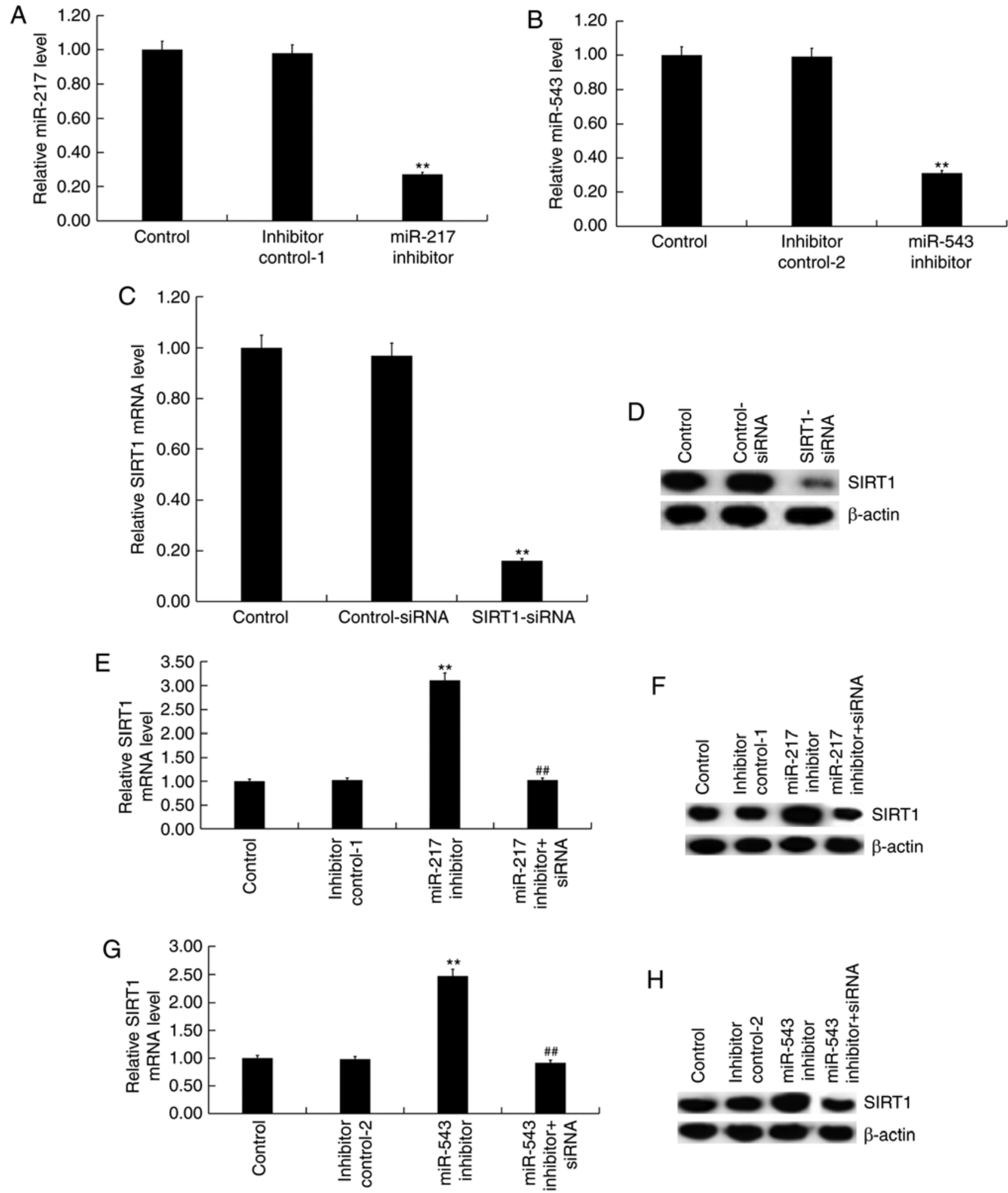

Figure 4. miR-217 and miR-543 negatively regulate the expression of SIRT1 in H9C2 cells. H9C2 cells were transfected with (A) miR-217 or (B) miR-543 inhibitors, and the levels of miR-217 and miR-543 in H9C2 cells were detected using RT-qPCR analysis. H9C2 cells were transfected with control-siRNA or SIRT1-siRNA, and the (C) mRNA and (D) protein expression levels of SIRT1 were detected using RT-qPCR and western blotting. H9C2 cells were transfected with inhibitor control-1, miR-217 inhibitor or miR-217 inhibitor + SIRT1-siRNA, and the (E) mRNA and (F) protein expression levels of SIRT1 were detected using RT-qPCR and western blotting. H9C2 cells were transfected with inhibitor control-1, miR-543 inhibitor or miR-543 inhibitor + SIRT1-siRNA, and the (G) mRNA and (H) protein expression levels of SIRT1 were detected using RT-qPCR and western blotting. ${ }^{* *} \mathrm{P}<0.01$ vs. corresponding control; ${ }^{\# \#} \mathrm{P}<0.01$ vs. corresponding miR inhibitor. siRNA, small interfering RNA; miR, microRNA; SIRT1, sirtuin 1; RT-qPCR, reverse transcription-quantitative PCR; inhibitor control-1, miR-217 inhibitor control; inhibitor control-2, miR-543 inhibitor control.

(version 2.5; Purdue University Cytometry Laboratories; www.cyto.purdue.edu/flowcyt/software/Catalog.htm).
ELISA. To measure the production of inflammatory cytokines interleukin (IL)- 6 and IL-1 $\beta$ in cell culture medium, the 

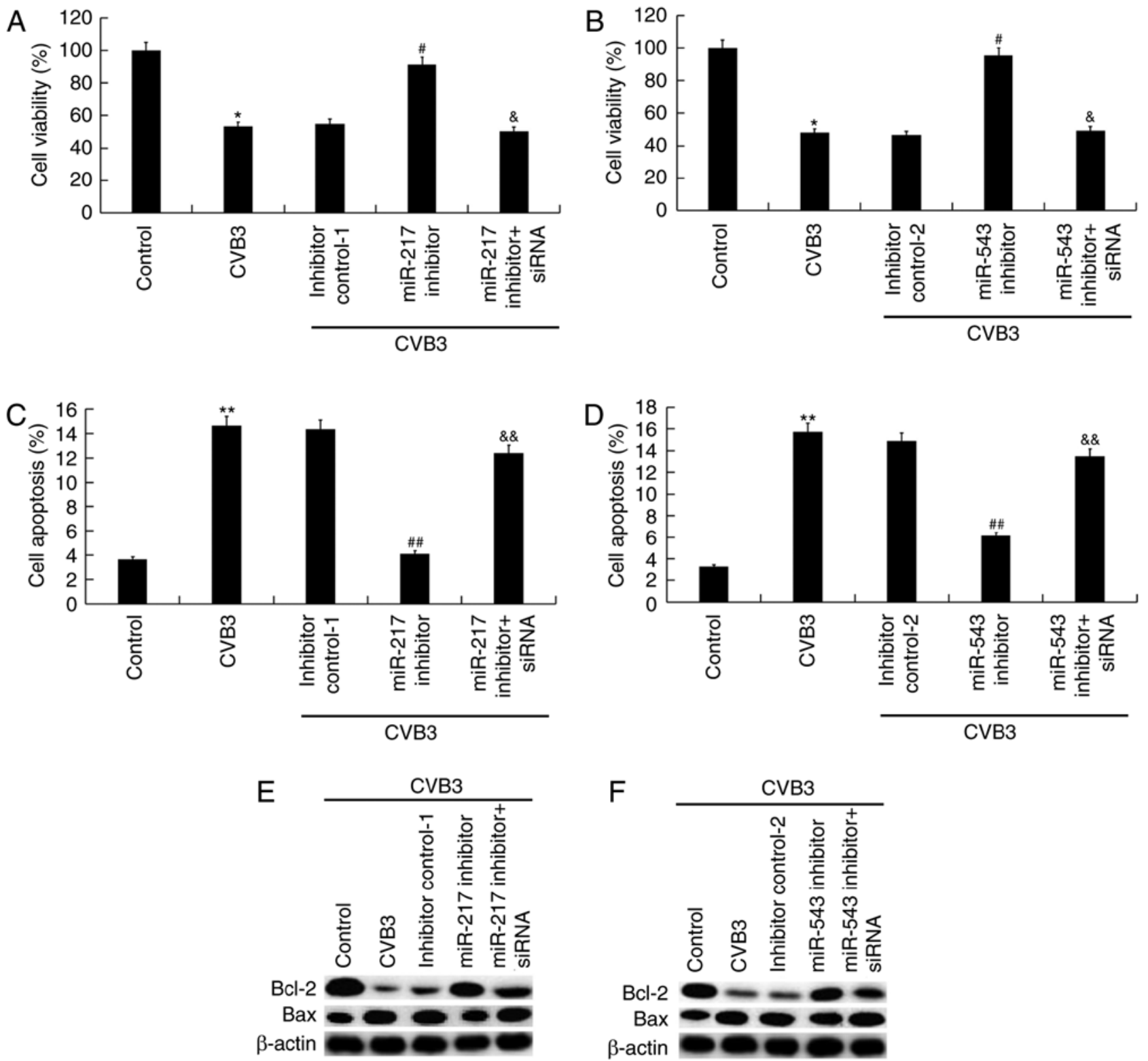

Figure 5. Role of miR-217 and miR-543 on CVB3-infected H9C2 cells. H9C2 cells were transfected with miR-217 or miR-543 inhibitors, miR-217 or miR-543 inhibitor controls, miR-217 inhibitor + SIRT1-siRNA, or miR-543 inhibitor + SIRT1-siRNA for $48 \mathrm{~h}$ and then treated with $10^{4} \mathrm{PFU} / \mathrm{ml}$ CVB3 virus for $48 \mathrm{~h}$. Effects of (A) miR-217 and (B) miR-543 on cell viability of CVB3-infected H9C2 cells. Effect of (C) miR-217 and (D) miR-543 on cell apoptosis of CVB3-infected H9C2 cells. Effects of (E) miR-217 and (F) miR-543 on Bax and Bcl-2 protein expression levels in CVB3-infected H9C2 cells. ${ }^{*} \mathrm{P}<0.05,{ }^{* *} \mathrm{P}<0.01$ vs. corresponding control; ${ }^{\&} \mathrm{P}<0.05$, \&\& $\mathrm{P}<0.01$ vs. corresponding miR inhibitor. ${ }^{*} \mathrm{P}<0.05$, ${ }^{\# \#} \mathrm{P}<0.01$ vs. CVB3. CVB3, Coxsackievirus B3; miR, microRNA; SIRT1, sirtuin 1; siRNA, small interfering RNA; inhibitor control-1, miR-217 inhibitor control; inhibitor control-2, miR-543 inhibitor control.

culture supernatants of $\mathrm{H} 9 \mathrm{C} 2$ cells were collected, and the level of IL-6 (cat. no. ab100772), and IL-1ß (cat. no. ab100768) was detected by using ELISA kits (Abcam) following the manufacturer's instructions.

MDA and SOD detection. The SOD activity (cat. no. ab118970) and the level of MDA (cat. no. Ab118970) were determined by using commercially available kits (Abcam) following the manufacturer's protocols.

Automatic biochemical analysis. The contents of creatine kinase (CK-MB) and lactate dehydrogenase (LDH) in the peripheral blood of mice in different groups were detected according to the manufacturer's protocols (Beckman Coulter, Inc.).
Dual-luciferase reporter assay. TargetScan software (version 7.1; www.targetscan.org/vert_71) was used to predict the putative target genes of miR-217 and miR-543. SIRT1 was found to be a potential target of both miR-217 and miR-543. To confirm the targets and the putative binding sites, the wild-type (WT) 3'UTR of SIRT1 or the mutant (MUT) 3'UTR SIRT1 were cloned into the dual-luciferase reporter vector pmiR-RB-REPORT (Guangzhou RiboBio Co., Ltd.) following the manufacturer's instructions. The QuikChange Site-Directed Mutagenesis kit (Agilent Technologies, Inc.) was used to make a point mutation in the miR-217 and miR-543 binding domain on the 3'UTR of SIRT1. H9C2 cells were co-transfected with $100 \mathrm{ng}$ WT-SIRT1 or $100 \mathrm{ng}$ MUT-SIRT1 and $50 \mathrm{nM}$ miR-217 and miR-543 mimic or $50 \mathrm{nM}$ mimic 

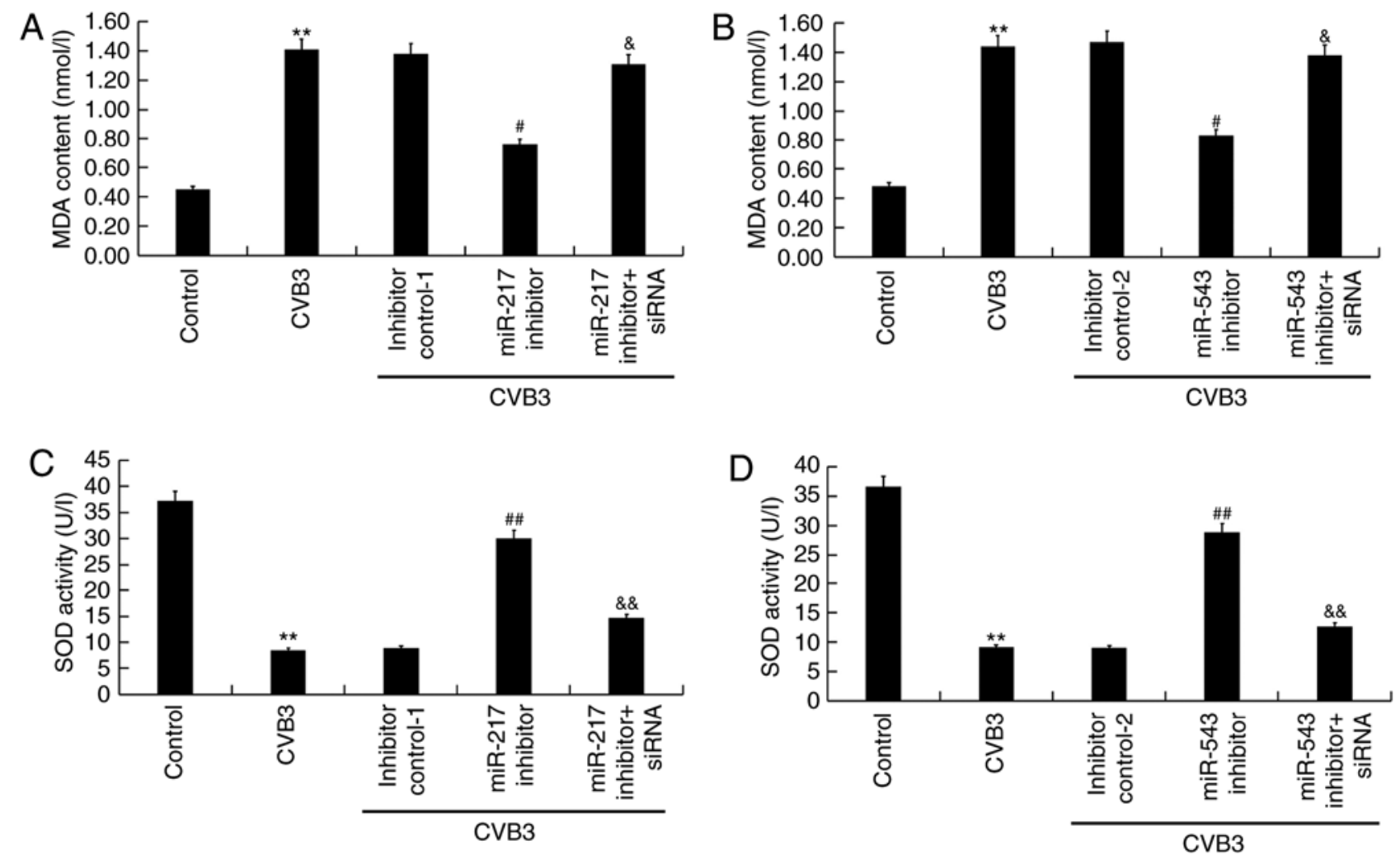

Figure 6. Effects of miR-217 and miR-543 on oxidative stress in CVB3-infected H9C2 cells. H9C2 cells were transfected with miR-217 or miR-543 inhibitors, miR-217 or miR-543 inhibitor controls, miR-217 inhibitor + SIRT1-siRNA, or miR-543 inhibitor + SIRT1-siRNA for $48 \mathrm{~h}$ and then treated with $10^{4} \mathrm{PFU} / \mathrm{ml}$ CVB3 virus for $48 \mathrm{~h}$. Effects of (A) miR-217 and (B) miR-543 on MDA levels in CVB3-infected H9C2 cells. Effect of (C) miR-217 and (D) miR-543 on SOD activity in CVB3-infected $\mathrm{H} 9 \mathrm{C} 2$ cells. ${ }^{* *} \mathrm{P}<0.01$ vs. corresponding control; ${ }^{\circledR} \mathrm{P}<0.05$, ${ }^{\&}{ }^{\&} \mathrm{P}<0.01$ vs. corresponding miR inhibitor; ${ }^{*} \mathrm{P}<0.05,{ }^{\# \#} \mathrm{P}<0.01$ vs. CVB3 CVB3, Coxsackievirus B3; miR, microRNA; SIRT1, sirtuin 1; siRNA, small interfering RNA; SOD, superoxide dismutase; MDA, malondialdehyde; inhibitor control-1, miR-217 inhibitor control; inhibitor control-2, miR-543 inhibitor control.

control using Lipofectamine ${ }^{\circledR} 2000$ (Invitrogen; Thermo Fisher Scientific, Inc.) following the manufacturer's protocol. After $48 \mathrm{~h}$, luciferase activity was determined by using a Dual-luciferase ${ }^{\circledR}$ reporter assay system (Promega Corporation) according to the manufacturer's protocol. Firefly luciferase activity was normalized to Renilla luciferase activity.

Statistical analysis. All data are presented as the mean \pm SD from $>3$ independent experiments. All statistical analyses were performed using SPSS 17.0 software (SPSS, Inc.). Two groups were compared using Student's t-test. One-way ANOVA followed by Tukey's post hoc test was used to compare multiple groups. $\mathrm{P}<0.05$ was considered to indicate a statistically significant difference.

\section{Results}

miR-217 and miR-543 are upregulated in viral myocarditis. The levels of miR-217 and miR-543 were detected in the blood samples collected from children with viral myocarditis and in the blood samples from healthy volunteers using RT-qPCR, and the results indicated that the levels of miR-217 and miR-543 in the blood samples from children with viral myocarditis was significantly higher than that in the blood samples from the healthy volunteers $(\mathrm{P}<0.01$; Fig. 1A and B). In addition, the levels of miR-217 and miR-543 in the blood and myocardial tissues of CVB3-infected mice were detected. As shown in Fig. 1C and D, CVB3 infection significantly increased the levels of CK-MB and LDH in the blood of CVB3 infected mice (both $\mathrm{P}<0.01$; Fig. 1C and D), indicating the successful establishment of an in vivo model of viral myocarditis (37). As expected, the levels of miR-217 and miR-543 in the blood and myocardial tissues of CVB3-infected mice were significantly increased compared with the control group (all $\mathrm{P}<0.01$; Fig. 1E-H). In addition, an in vitro model of viral myocarditis was also established in the present study, and, compared with the control group, the levels of miR-217 and miR-543 were significantly increased in H9C2 cells infected with CVB3 (both $\mathrm{P}<0.01$; Fig. 1I and J). Collectively, the present results suggested that miR-217 and miR-543 may play an important role in the development of viral myocarditis.

SIRT1 is a target of $m i R-217$ and miR-543. To examine the role of miR-217 and miR-543 in viral myocarditis, the putative targets of these two miRNAs were investigated. TargetScan was used to predict the potential targets of miR-217 and miR-543, and SIRT1 was found to be a potential target of both miR-217 and miR-543 (Fig. 2A and B). Results from the luciferase reporter assay indicated that the luciferase activity was significantly reduced in $\mathrm{H} 9 \mathrm{C} 2$ cells co-transfected with miR-217 and miR-543 mimics and SIRT1-WT reporter plasmids, but co-transfection with miR-217 and miR-543 mimic and SIRT1-MUT reporter plasmids did not alter the luciferase 

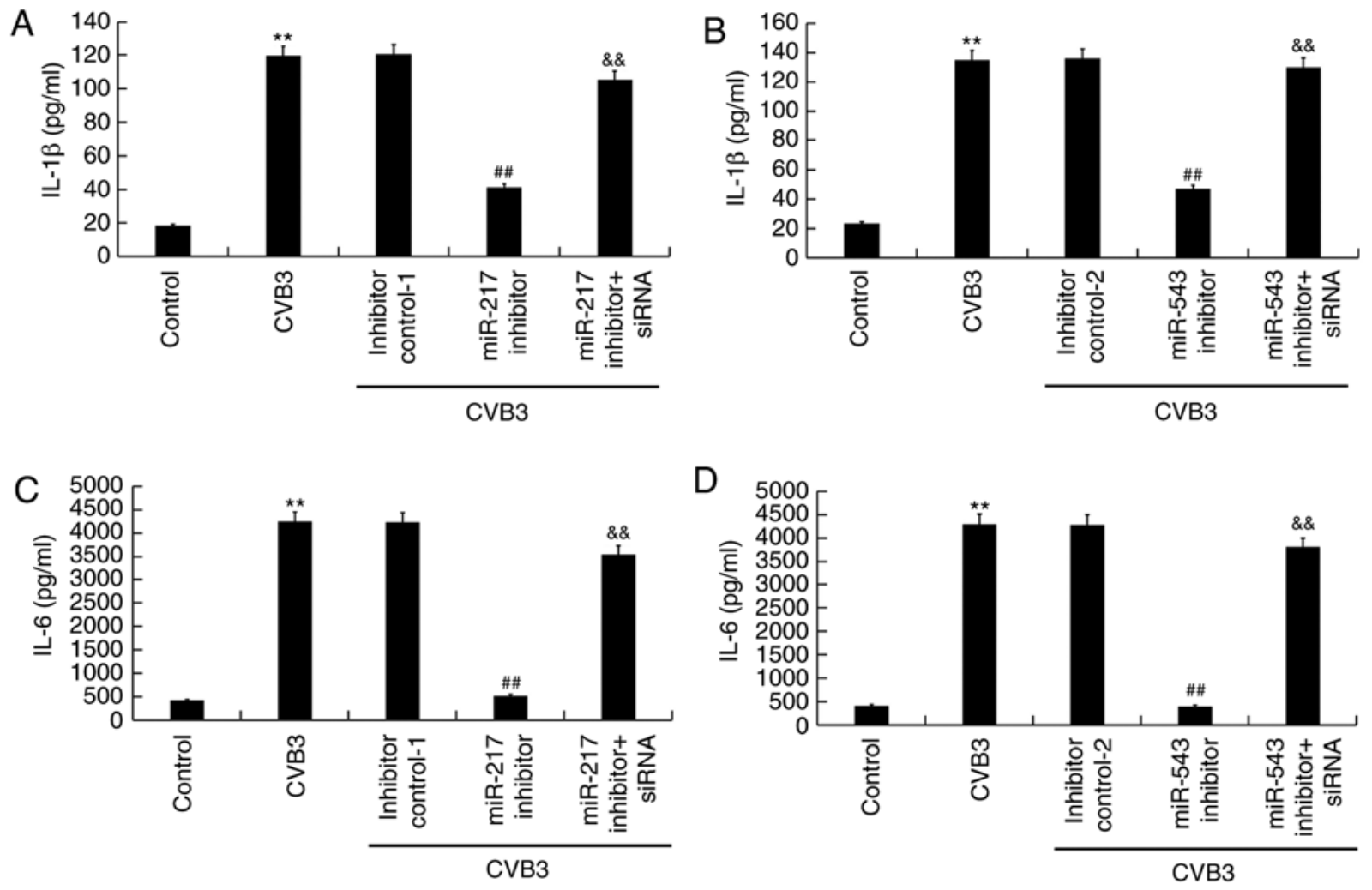

Figure 7. Effects of miR-217 and miR-543 on inflammatory response in CVB3-infected H9C2 cells. H9C2 cells were transfected with miR-217 or miR-543 inhibitors, miR-217 or miR-543 inhibitor controls, miR-217 inhibitor + SIRT1-siRNA, or miR-543 inhibitor + SIRT1-siRNA for $48 \mathrm{~h}$ and then treated with $10^{4} \mathrm{PFU} / \mathrm{ml}$ CVB3 virus for $48 \mathrm{~h}$. Effects of (A) miR-217 and (B) miR-543 on IL-1 $\beta$ levels in CVB3-infected H9C2 cells. Effect of (C) miR-217 and (D) miR-543 on IL-6 levels in CVB3-infected H9C2 cells. ${ }^{* *} \mathrm{P}<0.01$ vs. corresponding control; ${ }^{\& \&} \mathrm{P}<0.01$ vs. corresponding miR inhibitor; ${ }^{\# \# /} \mathrm{P}<0.01$ vs. CVB3. CVB3, Coxsackievirus B3; miR, microRNA; SIRT1, sirtuin 1; siRNA, small interfering RNA; IL, interleukin; inhibitor control-1, miR-217 inhibitor control; inhibitor control-2, miR-543 inhibitor control.

activity (both $\mathrm{P}<0.01$; Fig. 2C and D). Collectively, the present results indicated that SIRT1 was a target of both miR-217 and miR-543.

SIRT1 is downregulated in viral myocarditis. As shown in Fig. 3A, the mRNA level of SIRT1 in the blood samples from children with viral myocarditis was significantly lower compared with healthy volunteers $(\mathrm{P}<0.01$; Fig. 3A). Compared with the control group, the mRNA levels of SIRT1 in the blood $(\mathrm{P}<0.01$; Fig. 3B) and myocardial tissues $(\mathrm{P}<0.01$; Fig. 3D) of CVB3-infected mice were significantly decreased. The protein levels of SIRT1 in the blood (Fig. 3C) and myocardial tissues (Fig. 3E) of CVB3-infected mice were also markedly decreased. In addition, SIRT1 mRNA (P<0.01; Fig. 3F) and protein (Fig. 3G) expression levels were also reduced in H9C2 cells infected with CVB3. The present results further suggested that miR-217 and miR-543 may play critical roles in the development of viral myocarditis.

miR-217 and miR-543 downregulation increases cell proliferation and suppresses cell apoptosis in CVB3-infected H9C2 cells. To investigate the effect of miR-217 and miR-543 on myocarditis, H9C2 cells were transfected with the inhibitor control of miR-217 inhibitor, inhibitor control of miR-543 inhibitor, miR-217 inhibitor, miR-543 inhibitor, miR-217 inhibitor + SIRT1-siRNA or miR-543 inhibitor + SIRT1-siRNA for $48 \mathrm{~h}$. Subsequently, H9C2 cells were infected with CVB3 virus. miR-217 inhibitor and miR-543 inhibitor significantly reduced the expression levels of miR-217 and miR-543 in H9C2 cells, respectively ( $\mathrm{P}<0.01$; Fig. 4A and B). SIRT1-siRNA significantly inhibited the mRNA $(\mathrm{P}<0.01$; Fig. 4C) and protein (Fig. 4D) expression of SIRT1 in H9C2 cells. miR-217 inhibitor $(\mathrm{P}<0.01$; Fig. 4E) and miR-543 inhibitor $(\mathrm{P}<0.01$; Fig. $4 \mathrm{G})$ significantly increased the mRNA expression of SIRT1 in H9C2 cells, and these effects were reversed by SIRT1-siRNA (both $\mathrm{P}<0.01$; Fig. $4 \mathrm{E}$ and $\mathrm{G}$ ). The protein expression levels of SIRT1 increased after transfection with miR inhibitors and decreased following SIRT1-siRNA transfection (Fig. 4F and $\mathrm{H}$ ).

In addition, the results of CCK- 8 assay suggested that the decreased cell viability caused by CVB3 infection was significantly reversed following transfection with miR-217 inhibitor $(\mathrm{P}<0.05$; Fig. 5A) and miR-543 inhibitor ( $\mathrm{P}<0.05$; Fig. 5B), and these changes were significantly eliminated by SIRT1-siRNA (both $\mathrm{P}<0.05$; Fig. 5A and B). Cell apoptosis assay indicated that the increased cell apoptosis caused by CVB3 infection was significantly decreased by miR-217 inhibitor $(\mathrm{P}<0.01$; Fig. 5C) and miR-543 inhibitor $(\mathrm{P}<0.01$; Fig. 5D), and these changes were significantly suppressed by SIRT1-siRNA (both $\mathrm{P}<0.01$; Fig. 5C and D). In addition, the decrease in the protein expression levels of Bcl-2 and Bax caused by CVB3 infection was significantly reversed by miR-217 inhibitor (Fig. 5E) and miR-543 inhibitor (Fig. 5F), and these changes were suppressed by SIRT1-siRNA. 
A
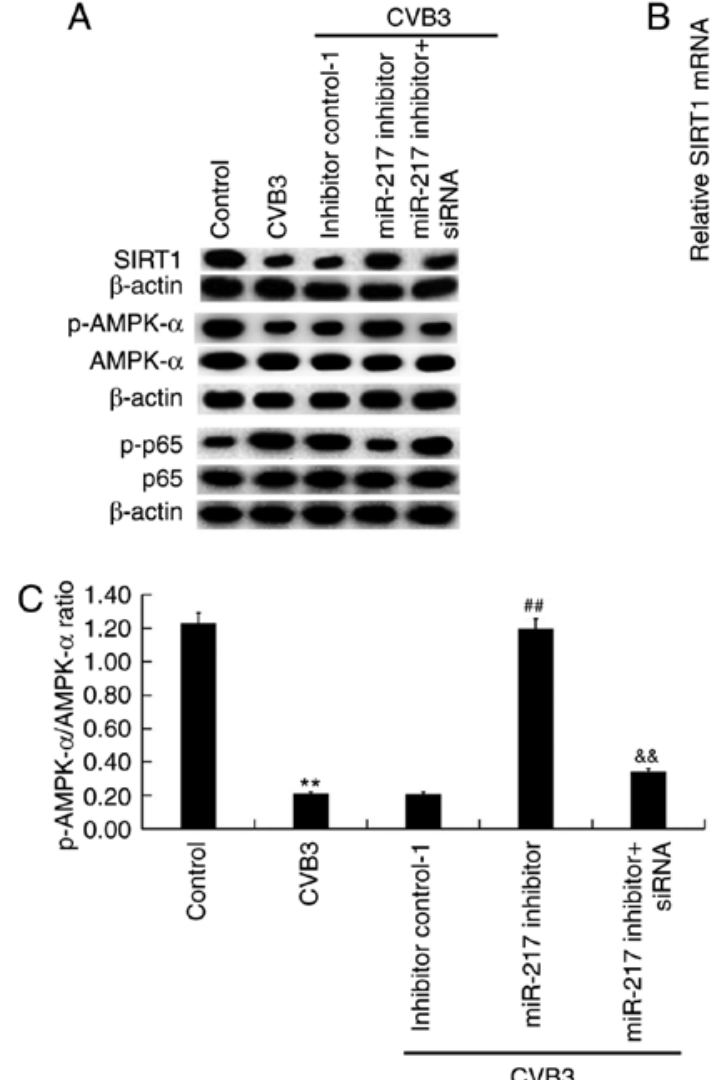

B

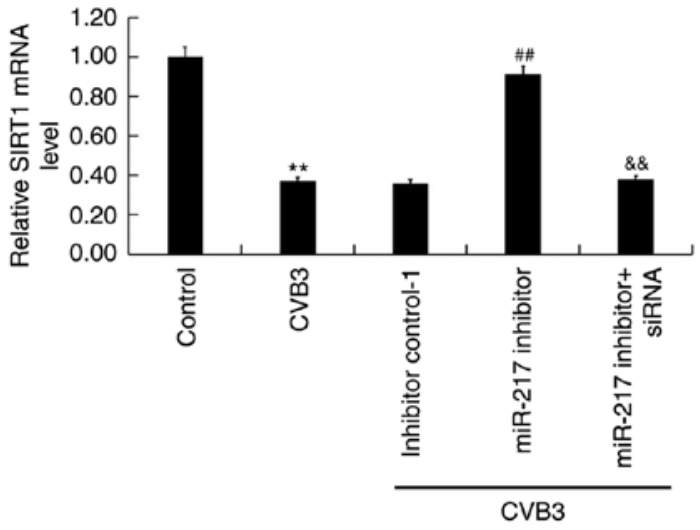

E

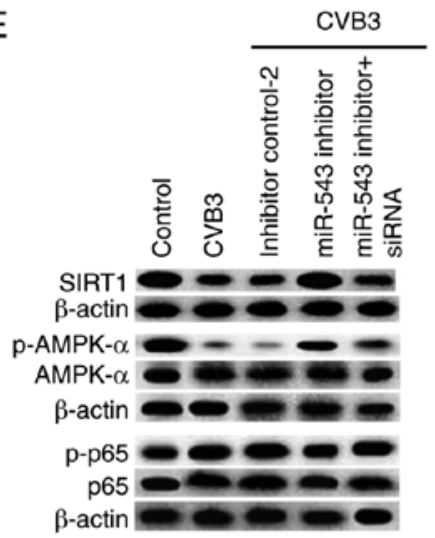

G

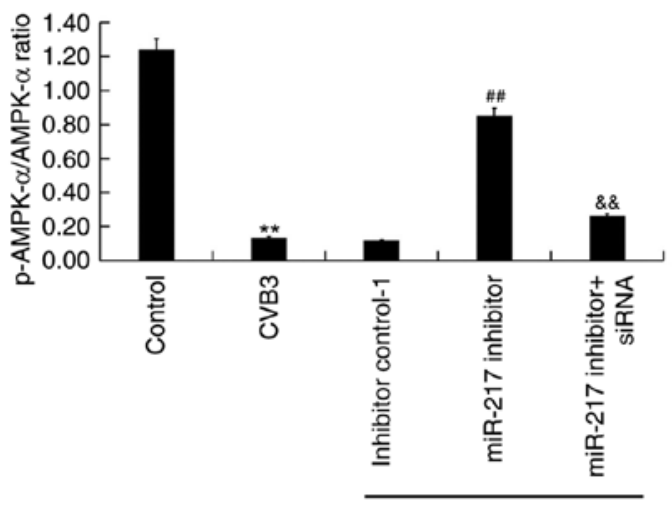

CVB3

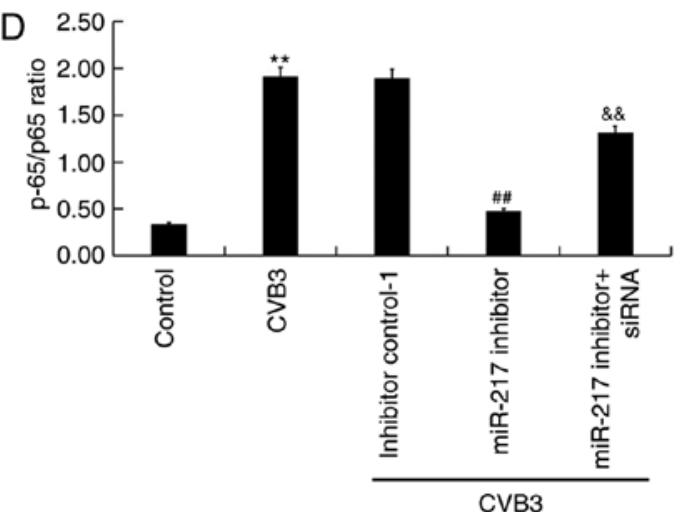

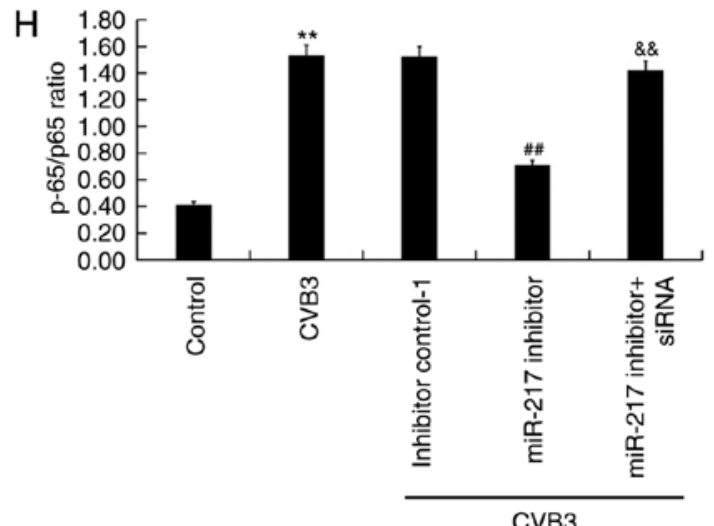

CVB3

Figure 8. Effects of miR-217 and miR-543 on the SIRT1/AMPK- $\alpha$ /NF- $\mathrm{kB}$ pathway in CVB3-infected H9C2 cells. H9C2 cells were transfected with miR-217 or miR-543 inhibitors, miR-217 or miR-543 inhibitor controls, miR-217 inhibitor + SIRT1-siRNA, or miR-543 inhibitor + SIRT1-siRNA for $48 \mathrm{~h}$ and then treated with $10^{4} \mathrm{PFU} / \mathrm{ml} \mathrm{CVB3}$ virus for $48 \mathrm{~h}$. Effects of miR-217 on the (A) protein and (B) mRNA expression levels of SIRT1, (C) p-AMPK- $\alpha / \mathrm{AMPK}-\alpha$ ratio and (D) p-p65/p65 ratio in CVB3-infected H9C2 cells. Effects of miR-217 on the (E) protein and (F) mRNA expression levels of SIRT1, (G) p-AMPK- $\alpha / A M P K-\alpha$ ratio and $(\mathrm{H}) \mathrm{p}$-p65/p65 ratio in CVB3-infected $\mathrm{H} 9 \mathrm{C} 2$ cells. ${ }^{* * *} \mathrm{P}<0.01$ vs. corresponding control; \&\& $\mathrm{P}<0.01$ vs. corresponding miR inhibitor; ${ }^{\# \#} \mathrm{P}<0.01$ vs. CVB3. p-, phosphorylated; AMPK- $\alpha$, AMP-activated protein kinase- $\alpha$; CVB3, Coxsackievirus B3; miR, microRNA; SIRT1, sirtuin 1; siRNA, small interfering RNA; inhibitor control-1, miR-217 inhibitor control; inhibitor control-2, miR-543 inhibitor control. 
miR-217 and miR-543 downregulation decreases oxidative stress in CVB3-infected H9C2 cells. To assess the oxidative stress, the level of MDA (an indicator of lipid peroxidation) (40) and the activity of SOD (an enzyme involved in the removal of free radicals) (41) were determined. The presented findings suggested that compared with the control group, CVB3 infection significantly enhanced the level of MDA $(\mathrm{P}<0.01)$ and inhibited SOD activity $(\mathrm{P}<0.01)$ in $\mathrm{H} 9 \mathrm{C} 2$ cells. Compared with the CVB3 infection group, miR-217 inhibitor significantly decreased MDA levels ( $\mathrm{P}<0.05$; Fig. 6A) and increased SOD activity $(\mathrm{P}<0.01$; Fig. 6C), and these changes were suppressed by SIRT1-siRNA. miR-543 served a similar role in regulating MDA level and SOD activity (Fig. 6B and D).

miR-217 and miR-543 downregulation reduces inflammatory response in CVB3-infected $\mathrm{H} 9 \mathrm{C} 2$ cells. To study the effect of miR-217 inhibitor and miR-543 inhibitor on inflammatory response in CVB3-infected $\mathrm{H} 9 \mathrm{C} 2$ cells, the levels of IL- $1 \beta$ and IL- 6 were measured by ELISA. It was found that, compared with the control group, the levels of IL-1 $\beta$ and IL- 6 in CVB3-infected H9C2 cells increased significantly $(\mathrm{P}<0.01)$. The increased levels of IL-1 $\beta$ and IL- 6 in CVB3-infected H9C2 cells were significantly reduced by miR-217 inhibitor (both $\mathrm{P}<0.01$; Fig. 7A and $\mathrm{C}$ ) and miR-543 inhibitor (both $\mathrm{P}<0.01$; Fig. 7B and D). Notably, the effects of miR-217 and miR-543 inhibitors were suppressed by SIRT1-siRNA.

Effect of miR-217 and miR-543 downregulation on the SIRT1/AMPK- $\alpha / N F-\kappa B$ pathway in CVB3-infected $H 9 C 2$ cells. The activity of the SIRT1/AMPK- $\alpha / \mathrm{NF}-\kappa \mathrm{B}$ pathway in CVB3-infected H9C2 cells was then analyzed. As shown in Fig. 8, CVB3 infection markedly inhibited SIRT1 protein (Fig. 8A and E) expression and significantly reduced SIRT1 mRNA ( $\mathrm{P}<0.01$; Fig. 8B and F) levels, decreased p-AMPK- $\alpha$ protein level and $\mathrm{p}-\mathrm{AMPK}-\alpha / \mathrm{AMPK}-\alpha$ ratio (Fig. $8 \mathrm{~A}$, $\mathrm{C}, \mathrm{E}$ and $\mathrm{G}$ ), and promoted the phosphorylation level of p65 protein and p-p65/p65 ratio (Fig. 8A, D, E and $\mathrm{H}$ ) in H9C2 cells. Compared with the CVB3 group, miR-217 (Fig. 8A-D) and miR-543 (Fig. 8E-H) inhibition notably increased SIRT1 and p-AMPK- $\alpha$ expression levels, and p-AMPK- $\alpha /$ AMPK- $\alpha$ ratio, and decreased p-p65 protein level and p-p65/p65 ratio. SIRT1 siRNA significantly reversed the effects of miR-217 and miR-543 inhibition on the activity of the SIRT1/AMPK- $\alpha / \mathrm{NF}-\kappa \mathrm{B}$ pathway $(\mathrm{P}<0.01$; Fig. 8$)$.

\section{Discussion}

The present study suggested that miR-217 and miR-543 were significantly upregulated in viral myocarditis. SIRT1, a target of miR-217 and miR-543, was significantly downregulated in viral myocarditis. CVB3 infection significantly reduced $\mathrm{H} 9 \mathrm{C} 2$ cell proliferation, induced $\mathrm{H} 9 \mathrm{C} 2$ cell apoptosis, upregulated the production of IL-6, IL-1 $\beta$, and MDA content, and inhibited SOD activity. Compared with the CVB3 infection group, downregulation of miR-217 and miR-543 significantly increased cell proliferation, reduced cell apoptosis, decreased the synthesis of IL-6, IL-1 $\beta$, decreased the level of MDA, and increased SOD activity. The effects of miR-217 and miR-543 inhibition on CVB3-infected cells were reversed by SIRT1 knockdown. The present results suggested that miR-217 and
miR-543 may be novel therapeutic targets for treating viral myocarditis.

Viral myocarditis is a clinically common disease in children and its incidence is increasing (42). The clinical manifestations of viral myocarditis are not typical, and if the diagnosis and treatment are not timely, the prognosis of pediatric patients can be seriously affected (42). Therefore, it is urgent to find new effective diagnostic markers and therapeutic targets for viral myocarditis. Numerous previous studies have shown that miRNAs play important roles in the occurrence and development of viral myocarditis (19-21). In the present study, it was found that the levels of miR-217 and miR-543 in blood samples from children with viral myocarditis were significantly higher than that in blood samples from healthy volunteers. It was also found that miR-217 and miR-543 were upregulated in both in vivo and in vitro model of viral myocarditis induced by CVB3 infection $(37,38)$. The present findings suggested a potential role for miR-217 and miR-543 in viral myocarditis. Then, to examine the role of miR-217 and miR-543 in viral myocarditis, the relationship between SIRT1, miR-217 and miR-543 was investigated in cardiomyocytes using H9C2 cells, and the present results indicated that SIRT1 was a direct target of both miR-217 and miR-543 in H9C 2 cells. Additionally, SIRT1 was found to be downregulated in patients with viral myocarditis, and in mice and H9C2 cells infected with CVB3.

Pathological changes of cardiomyocytes are the main pathological alterations occurring in viral myocarditis, and these changes are due to direct viral and immune-mediated damages to cardiomyocytes (43). In addition, the present study investigated the effects of miR-217 and miR-543 on CVB3-infected H9C2 cells. In line with a previous study (38), it was found that CVB3 infection significantly inhibited H9C2 cell viability and induced cell apoptosis. miR-217 and miR-543 inhibition significantly promoted H9C2 cell viability and inhibited H9C2 cell apoptosis. Inflammatory response and oxidative stress play a key role in the pathological development of viral myocarditis. Continuous chronic inflammation can induce myocardial cell necrosis, cardiac hypertrophy and cardiomyocyte apoptosis, which can lead to heart failure (44). In the present study, the effects of miR-217 and miR-543 inhibition on inflammatory response and oxidative stress were examined in CVB3-infected H9C2 cells. The present findings suggested that inhibition of miR-217 and miR-543 significantly decreased CVB3-mediated upregulation of IL-6, IL-1 $\beta$ and MDA, and reversed CVB3-mediated inhibition of SOD activity, indicating the potential of miR-217 and miR-543 inhibition in suppressing the inflammatory response and oxidative stress in CVB3-infected H9C2 cells. A previous study demonstrated that the activation of the AMPK $\alpha$-SIRT1 pathway prevents $\mathrm{NF}-\kappa \mathrm{B}$ inflammation (45). Therefore, to examine the molecular mechanism of miR-217 and miR-543 in CVB3-infected H9C2 cells, the SIRT1/AMPK- $\alpha / \mathrm{NF}-\kappa \mathrm{B}$ pathway was investigated in the present study. The present results showed that CVB3 infection significantly inhibited SIRT1 protein and mRNA levels, decreased p-AMPK- $\alpha$ protein level and p-AMPK- $\alpha / \mathrm{AMPK}-\alpha$ ratio, and promoted p-p65 protein level and p-p65/p65 ratio in H9C2 cells, and these alterations were significantly reversed by miR-217 and miR-543 inhibition. Notably, the effects of miR-217 and miR-543 inhibition on CVB3-infected H9C2 cells were suppressed following SIRT1 silencing. 
Collectively, the present study suggested that miR-217 and miR-543 were significantly upregulated in viral myocarditis, and miR-217 and miR-543 inhibition may attenuate viral myocarditis by inhibiting the apoptosis of cardiomyocytes and preventing the inflammatory response and oxidative stress by targeting SIRT1. The present results suggested that miR-217 and miR-543 may be novel potential therapeutic targets for the treatment of viral myocarditis.

\section{Acknowledgements}

Not applicable.

\section{Funding}

No funding was received.

\section{Availability of data and materials}

The datasets generated and analyzed during the present study are available from the corresponding author on reasonable request.

\section{Authors' contributions}

KX designed the study, and collected and interpreted the data. YZ contributed to the acquisition of the data, manuscript preparation and literature search. DS performed the statistical analysis. All authors read and approved the final manuscript.

\section{Ethics approval and consent to participate}

Informed consent was obtained from each patient and the parents or the legal guardians of the patients. The use of human samples was approved by The Ethics Committee of Wuhan Children's Hospital. Animal experiments were approved by The Animal Ethics Committee of Tongji Medical College, Huazhong University of Science and Technology.

\section{Patient consent for publication}

Not applicable.

\section{Competing interests}

The authors declare that they have no competing interests.

\section{References}

1. Yajima T: Viral myocarditis: Potential defense mechanisms within the cardiomyocyte against virus infection. Future Microbiol 6: 551-566, 2011.

2. Gaaloul I, Riabi S, Harrath R, Evans M, Salem NH, Mlayeh S, Huber $\mathrm{S}$ and Aouni M: Sudden unexpected death related to enterovirus myocarditis: Histopathology, immunohistochemistry and molecular pathology diagnosis at post-mortem. BMC Infect Dis 12: 212, 2012.

3. Wang T, Zhang J, Xiao A, Liu W, Shang Y and An J: Melittin ameliorates CVB3-induced myocarditis via activation of the HDAC 2 -mediated GSK-3 $\beta / \mathrm{Nrf} 2 / \mathrm{ARE}$ signaling pathway. Biochem Biophys Res Commun 480: 126-131, 2016.
4. Márquez-González H, López-Gallegos D, GonzálezEspinosa AM, Zamudio-López JO and YáñezGutiérrez L: Effect of immune therapy in the prognosis of viral myocarditis in pediatric patients. Rev Med Inst Mex Seguro Soc 54 (Suppl 3): S296-S301, 2016 (In Spanish).

5. Yu M, Long Q, Li HH, Liang W, Liao YH, Yuan J and Cheng X: IL-9 inhibits viral replication in coxsackievirus B3-induced myocarditis. Front Immunol 7: 409, 2016.

6. Wang C, Dong $\mathrm{C}$ and Xiong S: IL-33 enhances macrophage M2 polarization and protects mice from CVB3-induced viral myocarditis. J Mol Cell Cardiol 103: 22-30, 2017.

7. Pollack A, Kontorovich AR, Fuster V and Dec GW: Viral myocarditis-diagnosis, treatment options, and current controversies. Nat Rev Cardiol 12: 670-680, 2015.

8. Rienks M, Papageorgiou A, Wouters K, Verhesen W, Leeuwen RV, Carai P, Summer G, Westermann D and Heymans SA novel 72-kDa leukocyte-derived osteoglycin enhances the activation of toll-like receptor 4 and exacerbates cardiac inflammation during viral myocarditis. Cell Mol Life Sci 74: 1511-1525, 2017.

9. Yue-Chun L, Guang-Yi C, Li-Sha G, Chao X, Xinqiao T, Cong L, Xiao-Ya D and Xiangjun Y: The protective effects of ivabradine in preventing progression from viral myocarditis to dilated cardiomyopathy. Front Pharmacol 7: 408, 2016.

10. Bartel DP: MicroRNAs: Genomics, biogenesis, mechanism, and function. Cell 116: 281-297, 2004.

11. Hammond SM: An overview of microRNAs. Adv Drug Deliv Rev 87: 3-14, 2015

12. Ghildiyal $M$ and Zamore PD: Small silencing RNAs: An expanding universe. Nat Rev Genet 10: 94-108, 2009.

13. Soifer HS, Rossi JJ and Saetrom P: MicroRNAs in disease and potential therapeutic applications. Mol Ther 15: 2070-2079, 2007.

14. Krol J, Loedige I and Filipowicz W: The widespread regulation of microRNA biogenesis, function and decay. Nat Rev Genet 11: 597-610, 2010.

15. O'Connell RM, Rao DS, Chaudhuri AA and Baltimore D: Physiological and pathological roles for microRNAs in the immune system. Nat Rev Immunol 10: 111-122, 2010.

16. Bardooli F, McAlindon E, Littlejohns B, Suleiman MS, Bucciarelli-Ducci C and Baumbach A: TCT-184 Early changes in circulating miRNA 133a are indicative of cardiac remodelling after 3 months in patients presenting with acute ST elevation myocardial infarction. J Am Coll Cardiol 68: B75-B76, 2016.

17. Wang Y, Ouyang M, Wang Q and Jian Z: MicroRNA-142-3p inhibits hypoxia/reoxygenation-induced apoptosis and fibrosis of cardiomyocytes by targeting high mobility group box 1 . Int J Mol Med 38: 1377-1386, 2016.

18. Singh GB, Raut SK, Khanna S, Kumar A, Sharma S, Prasad R and Khullar M: MicroRNA-200c modulates DUSP-1 expression in diabetes-induced cardiac hypertrophy. Mol Cell Biochem 424: 1-11, 2017.

19. Corsten MF, Papageorgiou A, Verhesen W, Carai P, Lindow M, Obad S, Summer G, Coort SL, Hazebroek M, van Leeuwen R, et al: MicroRNA profiling identifies microRNA-155 as an adverse mediator of cardiac injury and dysfunction during acute viral myocarditis. Circ Res 111: 415-425, 2012.

20. Corsten MF, Dennert R, Jochems S, Kuznetsova T, Devaux Y, Hofstra L, Wagner DR, Staessen JA, Heymans S and Schroen B: Circulating MicroRNA-208b and MicroRNA-499 reflect myocardial damage in cardiovascular disease. Circ Cardiovasc Genet 3: 499-506, 2010.

21. Bao JL and Lin L: MiR-155 and miR-148a reduce cardiac injury by inhibiting NF- $\kappa B$ pathway during acute viral myocarditis. Eur Rev Med Pharmacol Sci 18: 2349-2356,2014.

22. Nogueiras R, Habegger KM, Chaudhary N, Finan B, Banks AS, Dietrich MO, Horvath TL, Sinclair DA, Pfluger PT and Tschöp MH: Sirtuin 1 and sirtuin 3: Physiological modulators of metabolism. Physiol Rev 92: 1479-1514, 2012.

23. da Cunha MSB and Arruda SF: Tucum-do-Cerrado (Bactris setosa Mart.) may promote anti-aging effect by upregulating SIRT1-Nrf2 pathway and attenuating oxidative stress and inflammation. Nutrients 9: pii: E1243, 2017.

24. Rada P, Pardo V, Mobasher MA, García-Martínez I, Ruiz L, González-Rodríguez Á, Sanchez-Ramos C, Muntané J, Alemany S, James LP, et al: SIRT1 controls acetaminophen hepatotoxicity by modulating inflammation and oxidative stress. Antioxid Redox Signal 28: 1187-1208, 2018.

25. Chan SH, Hung CH, Shih JY, Chu PM, Cheng YH, Lin HC and Tsai KL: SIRT1 inhibition causes oxidative stress and inflammation in patients with coronary artery disease. Redox Biol 13: 301-309, 2017. 
26. Cheng YY, Kao CL, Ma HI, Hung CH, Wang CT, Liu DH, Chen PY and Tsai KL: SIRT1-related inhibition of pro-inflammatory responses and oxidative stress are involved in the mechanism of nonspecific low back pain relief after exercise through modulation of Toll-like receptor 4. J Biochem 158: 299-308, 2015.

27. Nguyen LT, Mak CH, Chen H, Zaky AA, Wong MG, Pollock CA and Saad S: SIRT1 attenuates kidney disorders in male offspring due to maternal high-fat diet. Nutrient 11: pii: E146, 2019.

28. Hwang JW, Yao H, Caito S, Sundar IK and Rahman I: Redox regulation of SIRT1 in inflammation and cellular senescence. Free Radic Biol Med 61: 95-110, 2013.

29. Guo R, Liu W, Liu B, Zhang B, Li W and Xu Y: SIRT1 suppresses cardiomyocyte apoptosis in diabetic cardiomyopathy: An insight into endoplasmic reticulum stress response mechanism. Int J Cardiol 191: 36-45, 2015.

30. Mao Q, Liang X, Wu Y and Lu Y: Resveratrol attenuates cardiomyocyte apoptosis in rats induced by coronary microembolization through SIRT1-mediated deacetylation of p53. J Cardiovasc Pharmacol Ther 24: 551-558, 2019.

31. Zhang WX, He BM, Wu Y, Qiao JF and Peng ZY: Melatonin protects against sepsis-induced cardiac dysfunction by regulating apoptosis and autophagy via activation of SIRT1 in mice. Life Sci 217: 8-15, 2019.

32. Ben Salem I, Boussabbeh M, Pires Da Silva J, Guilbert A, Bacha H, Abid-Essefi S and Lemaire C: SIRT1 protects cardiac cells against apoptosis induced by zearalenone or its metabolites $\alpha$ - and $\beta$-zearalenol through an autophagy-dependent pathway. Toxicol Appl Pharmacol 314: 82-90, 2017.

33. Li J, Dong G, Wang B, Gao W and Yang Q: miR-543 promotes gastric cancer cell proliferation by targeting SIRT1. Biochem Biophys Res Commun 469: 15-21, 2016.

34. Hu X, Chi L, Zhang W, Bai T, Zhao W, Feng Z and Tian H: Down-regulation of the miR-543 alleviates insulin resistance through targeting the SIRT1. Biochem Biophys Res Commun 468: 781-787, 2015.

35. Yin H, Liang X, Jogasuria A, Davidson NO and You M: miR-217 regulates ethanol-induced hepatic inflammation by disrupting sirtuin 1-lipin-1 signaling. Am J Pathol 185: 1286-1296, 2015.
36. Bayne K: Revised guide for the care and use of laboratory animals available. American physiological society. Physiologist 39: 199, 208-211, 1996.

37. Xin L, Ma X, Xiao Z, Yao H and Liu Z: Coxsackievirus B3 induces autophagy in HeLa cells via the AMPK/MEK/ERK and Ras/Raf/MEK/ERK signaling pathways. Infect Genet Evol 36: 46-54, 2015.

38. Qi L, Xin Q and Wenjun J: Inhibition of iNOS protects cardiomyocytes against coxsackievirus B3-induced cell injury by suppressing autophagy. Biomed Pharmacother 91: 673-679, 2017.

39. Livak KJ and Schmittgen TD: Analysis of relative gene expression data using real-time quantitative PCR and the 2(-Delta Delta C(T)) method. Methods 25: 402-408, 2001

40. Tsikas D: Assessment of lipid peroxidation by measuring malondialdehyde (MDA) and relatives in biological samples: Analytical and biological challenges. Anal Biochem 524: 13-30, 2017.

41. Wu JQ, Kosten TR and Zhang XY: Free radicals, antioxidant defense systems, and schizophrenia.Prog Neuropsychopharmacol Biol Psychiatry 46: 200-206, 2013.

42. Casadonte JR, Mazwi ML, Gambetta KE, Palac HL, McBride ME, Eltayeb OM, Monge MC, Backer CL and Costello JM: Risk factors for cardiac arrest or mechanical circulatory support in children with fulminant myocarditis. Pediatr Cardiol 38: 128-134, 2017

43. Simpson KE, Storch GA, Lee CK, Ward KE, Danon S, Simon CM, Delaney JW, Tong A and Canter CE: High frequency of detection by PCR of viral nucleic acid in the blood of infants presenting with clinical myocarditis. Pediatr Cardiol 37: 399-404, 2016.

44. Tse G, Yeo JM, Chan YW, Lai ET and Yan BP: What is the arrhythmic substrate in viral myocarditis? Insights from clinical and animal studies. Front Physiol 7: 308, 2016.

45. Tian Y, Ma J, Wang W, Zhang L, Xu J, Wang K and Li D: Resveratrol supplement inhibited the NF- $\kappa$ B inflammation pathway through activating AMPK $\alpha$-SIRT1 pathway in mice with fatty liver. Mol Cell Biochem 422: 75-84, 2016. 